\title{
Emotion as mediators of the relations between perceived supervisor support and psychological hardiness on employee cynicism
}

\author{
MICHAEL S. COLE* ${ }^{*}$ HEIKE BRUCH AND BERND VOGEL \\ University of St. Gallen, Institute for Leadership and HR Management, Dufourstrasse 40a, CH-900O \\ St. Gallen, Switzerland
}

\begin{abstract}
Summary In this study we explore whether emotion experienced at work mediates the relationships between perceived supervisor support, psychological hardiness, and employee cynicism. Data were collected from employees working at a medical technology company located in Switzerland. Mediational analyses showed that employees' positive and negative emotions experienced amidst an organizational crisis fully accounted for the relations between perceived supervisor support and cynicism and psychological hardiness and cynicism. Practical implications and directions for future research are discussed. Copyright (C) 2006 John Wiley \& Sons, Ltd.
\end{abstract}

\section{Introduction}

Cynicism is not a new construct. Interestingly, its roots can be traced as far back as ancient Greece and the philosopher Antisthene (Dean, Brandes, \& Dharwadkar, 1998). More recently, it has become the focus of study in a variety of social science disciplines and has been purported to exist in various forms, ranging from police cynicism to personality cynicism to societal/institutional cynicism (Andersson, 1996; Dean et al., 1998). Nonetheless, despite its extensive history, cynicism directed towards the organization has only recently emerged as a focal topic in the organizational behavior literature (Treadway et al., 2004) and remains in what has been characterized as the first stage of scientific research development (Wanous, Reichers, \& Austin, 2000).

As such, cynicism has no universally agreed upon definition (Andersson, 1996; Treadway et al., 2004). In the present study, we adopted Bedeian's definition of employee cynicism as an attitude resulting from a critical appraisal of the motives, actions, and values of one's employing organization (Bedeian, in press, p. 7). Thus, it is an evaluative judgment that stems from an individual's employment experiences and, when viewed in this way, Bedeian (in press) has argued that it is a

* Correspondence to: M. S. Cole, University of St. Gallen, Institute for Leadership and HR Management, Dufourstrasse 40a, CH9000 St. Gallen, Switzerland. E-mail: Michael.Cole@unisg.ch 
subjectively based construct susceptible to the same perceptual biases common to other attitudes. Irrespective of the accuracy or validity of the individuals' perceptions on which the employee cynicism construct is based, it is real in its consequences. Corroborated by empirical research, high levels of employee cynicism have been found to increase burnout (Johnson \& O'Leary-Kelly, 2003), lower satisfaction and commitment (Johnson \& O'Leary-Kelly, 2003; Treadway et al., 2004), and adversely affect in-role/extra-role behaviors (Andersson \& Bateman, 1997; Brandes, Dharwadkar, \& Dean, 1999).

Whereas studies have begun to show the effect that increased cynicism can have on organizational effectiveness, only a limited number of antecedents of employee cynicism have been empirically examined. For instance, empirical research has focused almost exclusively on specific targets for employee cynicism, such as cynicism about organizational change (Bommer, Rich, \& Rubin, 2005; Wanous et al., 2000) or business environmental factors (e.g., harsh layoffs, high executive compensation; Andersson \& Bateman, 1997; Kanter \& Mirvis, 1989) that fall outside of most organizational members' control. Although this research has advanced our understanding of how cynicism in organizations materializes, we argue that, at this relatively early stage of employee cynicism research, the process by which employee cynicism develops has not been fully explored. Indeed, if one considers the major antecedents as proposed by the most comprehensive theoretical model to date (see Andersson, 1996), it is apparent that empirical research has overlooked a number of salient individual-level predictors that have been theoretically linked to employee cynicism.

In the aforementioned study, Andersson (1996) identified various factors in the organization and job environment that were believed to be associated with contract violations and thereby contribute to increased levels of employee cynicism. According to Andersson (1996), for example, perceptions of poor organizational communication, unfair and discourteous interpersonal treatment, and managerial incompetence are all important factors predicted to increase levels of employee cynicism. Andersson (1996) further argued that individuals' dispositional attributes are likely to play an important role in the formation of the cynicism attitude. In one of only two empirical studies that have considered Andersson's conceptual model, Johnson and O'Leary-Kelly (2003) argued that cynicism was a reaction to employment-related social exchange violations. In support of their predictions, Johnson and O'Leary-Kelly reported that perceived psychological contract violations were associated with increased levels of cynicism among bank employees. Treadway et al. (2004), in their test of a model concerning leader political skill, treated perceived organizational support and trust in management as antecedents of employee cynicism. The negative correlations they report between higher levels of perceived organizational support and cynicism and higher levels of trust in management and cynicism are theoretically consistent with the logic presented by Andersson (1996).

From our review of the literature, it appears that the state of employee cynicism research is such that there is a lack of empirical research, in general, and on the antecedents of employee cynicism, in particular. For example, research reported by Johnson and O'Leary-Kelly (2003) and Treadway et al. (2004) recognized that individuals' perceptions of the work environment could significantly influence cynicism; however, they did not examine individuals' dispositional attributes as potential antecedents of employee cynicism (although Johnson \& O'Leary-Kelly, 2003 used dispositional attributes as control variables). As a consequence, previous research has provided only partial insight into the development of employee cynicism within organizations. Accordingly, empirical research that takes into account predictors from each of the aforementioned categories of antecedents - individuals' workplace perceptions and dispositional attributes — would provide a more integrated understanding with regard to the complexities associated with employee cynicism development. 
The current study seeks to address this gap in the literature by developing and empirically testing a model that considers both individuals' perceptions of their work environment and dispositional attributes as predictors of employee cynicism. Specifically, we examined two individual-level antecedents - perceived supervisor support and the individual disposition, psychological hardiness. With regard to the effect of perceived supervisor support, concepts related to social exchange theory have previously demonstrated that employee cynicism can be influenced by global beliefs concerning the extent to which the organization cares about their well-being (Treadway et al., 2004). Therefore, as agents of the organization, we suspect that supervisors' favorable treatment of employees will also have a positive effect in terms of decreased levels of employee cynicism. Psychological hardiness was examined because there is a growing body of research that has shown hardiness enhances resiliency in response to the ongoing demands and pressures of everyday life (Maddi, 2005), and it has been reported to increase levels of moral and subjective well-being (Florian, Mikulincer, \& Taubman, 1995; Maddi, 1999b). Moreover, because hardy individuals are optimists, they are more capable of finding positive meaning in their work and we expect this will result in the decrease of employee cynicism levels.

According to Andersson's (1996) model, however, the proposed relationships between employee cynicism and its predictors are not always straightforward and may even be indirect. In this regard, the research by Rousseau (1989) is believed to be particularly relevant. For instance, although unpleasant organizational events and unmet expectations are known to increase employee cynicism (Andersson, 1996; Johnson \& O'Leary-Kelly, 2003; Treadway et al., 2004), Rousseau's research demonstrates that such negative events ignite intense emotional reactions from employees. George (1996) has similarly characterized emotions as intense feelings that demand attention and have a specific target. Moreover, emotion research has shown that workplace features can create events or interactions within organizations that elicit emotion in employees, which, in turn, influence job attitudes (Brief \& Weiss, 2002). Therefore, it is plausible that employees' emotional reactions play a key role in the formation of high or low levels of employee cynicism. The infancy of the employee cynicism construct (Wanous et al., 2000), however, provides little empirical grounding for the employee emotion-cynicism relationship.

Indeed, although research has speculated on the role played by emotion in kindling employee cynicism (e.g., Bedeian, in press), no study to our knowledge has investigated whether employees' emotional reactions trigger cynicism development. Nonetheless, if we look beyond the cynicism literature and its use of psychological contract theory as a theoretical basis, we assert that Weiss and Cropanzano's (1996) Affective Events Theory (AET) possesses considerable promise for enhancing our understanding of the processes by which cynicism develops as a workplace attitude. Consistent with Andersson's (1996) conceptual model of employee cynicism, AET takes into account the influence that both organizational characteristics and individuals' dispositional attributes can have on job attitudes. Central to AET, however, is the assertion that emotional reactions are the conduit by which workplace conditions, and even individuals' dispositions, influence job attitudes (Weiss \& Cropanzano, 1996). In adopting this view, we contend that perceived supervisor support and psychological hardiness will indirectly predict the level of cynicism expressed by employees via employee emotion.

Thus, we built upon and extended previous research on employee cynicism by investigating three main questions that take into account elements of both Andersson's (1996) and Weiss and Cropanzano's (1996) theoretical frameworks. First, what is the contribution of perceived supervisor support and psychological hardiness on the experience of employee cynicism? Second, how important are both positive and negative emotion in the prediction of employee cynicism? Third, are emotions mediating mechanisms by which perceived supervisor support and/or psychological hardiness influence employee cynicism? Finally, with the above research questions in mind, what might be of particular interest is the study site where the data were collected. The organization was involved in 
settling a billion dollar class-action lawsuit due to its manufacturing of a faulty product. Employees were being forced to accept major change initiatives, many of which impacted them personally (e.g., divestment of business units, layoffs; a detailed description of these initiatives is provided later in the Methods section). Hence, because of the unique study setting, we were afforded the opportunity to test our study hypotheses using data collected in a real-world context of organizational crisis.

\section{Study Hypotheses}

\section{Perceived supervisor support and emotion}

It has recently been suggested that researchers begin to explore the effects of specific workenvironment features, including supervisory support and consideration, on the experience of positive and negative workplace emotions (Ashkanasy \& Daus, 2002; Fisher, 2002). For example, as a result of the multiple exchanges with supervisors, it is assumed that employees are exposed to a variety of situations that can elicit varied emotional reactions (Dasborough \& Ashkanasy, 2002; McCollKennedy \& Anderson, 2002). In this regard, past research has found that supervisors who are empathetic and responsive to employees' needs are particularly successful at managing employees' emotional reactions (e.g., Humphrey, 2002; Pescosolido, 2002). Thus, in the present study it is argued that supervisor support (or lack thereof) will be directly related to employees' emotional reactions.

Eisenberger, Stinglhamber, Vandenberghe, Sucharski, and Rhoades (2002) have defined perceived supervisor support as the degree to which employees form general impressions that their superiors appreciate their contributions, are supportive, and care about their subordinates' well-being. Sagie and Koslowsky (1994) observed that during times of organizational uncertainty (e.g., crises, change initiatives), employees have an increased need to perceive that their input is being considered, require frequent and accurate feedback, and must feel that resources are available to them if needed. Thus, we infer supervisor support plays a vital role in an employee's appraisal of a crisis situation. Whereas positive supervisor-employee interactions will increase the perception of supervisor support, negative interactions are expected to reduce it. More specifically, we propose employees will consider their interactions with supervisors as a criterion when evaluating the implications of organizational crises on their personal well-being, in part because employees use supervisor-employee interactions as cues to evaluate their relationships with their supervisors (Dasborough \& Ashkanasy, 2002; see also Ferris, Bhawuk, Fedor, \& Judge, 1995) as well as with their employing organization (Eisenberger et al., 2002). Conceptualized in this way, perceived supervisor support is understood to be an important factor in employees' definition of their contextual environment.

Rhoades and Eisenberger's (2002) meta-analysis showed employees with high, as contrasted with low, levels of perceived organizational support were more likely to experience positive affect. Although Rhoades and Eisenberger's study investigated the impact of perceived organizational support, important parallels can be drawn between their study and perceptions of supervisor support and the experience of workplace emotions. Eisenberger et al. (2002) found that employees inferred perceived organizational support from their supervisor's actions, in part because supervisors generally act as spokespersons for their organization. As a result, employees consider favorable treatment and support by their supervisor and, therefore the organization, as an indication that employees are cared for (Eisenberger et al.) and it signifies to employees that material aid and emotional support are available when needed (George, Reed, Ballard, Colin, \& Fielding, 1993). 
In keeping with this line of research, we suggest that the experience of positive emotion is the likely result of high-quality supervisor-employee exchanges. In contrast, low-quality exchange relationships are expected to result in employees feeling not only more negative emotions but also fewer positive emotions. Important to the present study is the expectation that positive and negative emotions will cooccur. ${ }^{1}$ In this regard, positive emotions are known to co-occur alongside negative emotions, particularly during periods of intense stress (Folkman \& Moskowitz, 2000; Fredrickson, 2001). Thus, when considered collectively, supportive and considerate supervisors are expected to elicit more positive emotions in their employees whereas a lack of support is predicted to not only generate negative emotions but also low positive emotions. We therefore suggest the following:

Hypothesis 1a: Perceived supervisor support will be positively related to positive emotion.

Hypothesis $1 b$ : Perceived supervisor support will be negatively related to negative emotion.

\section{Psychological hardiness and emotion}

Weiss and Cropanzano (1996) suggested individuals' dispositional characteristics act directly on affective reactions. Whereas research has previously examined the relationships between positive and negative trait affectivity and emotion (e.g., Fisher, 2002), we focused on psychological hardiness because it is reported to influence how individuals experience, interpret, and cope with stressful events and situations (Maddi, 1999a), and it has been shown to enhance performance, conduct, and morale (Maddi, 1999b). Hardiness has, however, only recently been discussed in terms of an organizational context (e.g., Maddi, Khoshaba, \& Pammenter, 1999). Due to its relative absence from the organizational behavior literature, we first introduce the psychological hardiness construct and describe its underlying mechanisms.

Psychological hardiness is a personality composite of beliefs about self and world involving the importance of a sense of commitment, control, and challenge (Kobasa, 1979; Maddi, 1999b). Commitment is defined as a 'tendency to involve oneself in (rather than experience alienation from) whatever one is doing or encounters' (Kobasa, Maddi, \& Kahn, 1982, p. 169). Control is a 'tendency to feel and act as if one is influential (rather than helpless) in the face of the varied contingencies of life' (Kobasa et al., 1982, p. 169). Finally, challenge is a 'belief that change rather than stability is normal in life and that the anticipation of changes are interesting incentives to growth rather than threats to security' (Kobasa et al., p. 169).

Hardy beliefs are reported to influence how individuals interpret and cope with stressful life circumstances (Maddi, 1999b). In particular, hardy individuals experience stressful situations in ways that are comparable to less hardy individuals, but hardy individuals appraise the potentially stressful situations as less threatening, thus helping to minimize the experience of distress (Bartone, Ursano, Wright, \& Ingraham, 1989; Britt, Adler, \& Bartone, 2001). For instance, Maddi (1999b) found hardy individuals, as compared to their non-hardy counterparts, appraised tasks as being more interesting and

\footnotetext{
${ }^{1}$ Our interest in the co-occurrence of positive and negative emotion calls attention to the on-going debate on whether positive and negative emotion are bipolar or independent constructs. This debate, however, has focused primarily on the momentary experience of affect and whether someone can simultaneously experience positive and negative emotions (for a review of the debate, see Russell \& Carroll, 1999). For the present study, the relationship between positive and negative emotion at any one given point in time was not of concern. Rather, we were interested in the experience of positive and negative emotion over a period of time.
} 
enjoyable (commitment), considered them as a matter of choice rather than obligatory (control), and as an important stimulus for personal growth (challenge). Hardy individuals also remain optimistic in their abilities to cope with stressful events. Hardy coping includes using problem-focused strategies that involve the mental feat of putting each stressful circumstance in a broader perspective in order to transform the stress into a benign experience (Florian et al., 1995). Thus, the defining feature of hardy persons is their innate ability to find positive meaning in life (Kobasa, 1979).

Considered collectively, then, hardy persons can be expected to show less emotion debilitation under extraordinary negative events and to rebound faster from them. Furthermore, they have been compared to optimists in how they perceive and cope with unpleasant events (Britt et al., 2001), and have been found to display decreased signs of depression, anxiety, and psychological distress (Florian et al., 1995; Rhonewalt \& Agustsdottir, 1984). These implications are the basis on which it has been suggested that hardiness promotes a positive emotional tone (Folkman \& Moskowitz, 2000; Maddi \& Kobasa, 1981). Based on the above evidence, hardy persons will be more likely to experience positive emotion and less likely to experience negative emotion. Accordingly, we hypothesize:

Hypothesis 2a: Psychological hardiness will be positively related to positive emotion.

Hypothesis $2 b$ : Psychological hardiness will be negatively related to negative emotion.

\section{Emotion and cynicism}

Whereas the concepts of mood and emotion are generally well understood, there remains ongoing discussion regarding the various classifications used to categorize these affective reactions. In short, the distinguishing feature between mood and emotion is seen in terms of diffuseness (Weiss \& Cropanzano, 1996). Research suggests that moods lack a person or object to which the affect is directed and do not involve a distinct contextual stimulus (Lazarus, 1991; Weiss \& Cropanzano, 1996). Emotions are described as focused, affective states that result from a reaction to a specific event. Therefore, in an organizational context, emotions - in contrast to moods - illustrate employees' feelings about incidents such as uncertainty of security or fundamental changes occurring in the organization.

Research has found that positive and negative emotion clusters are inversely related, i.e., as people become happier, they tend to become correspondingly less sad. Such findings have led some researchers (e.g., Green, Salovey, \& Truax, 1999) to question the independence between positive and negative emotions. Others would suggest, however, that positive and negative emotions are related but separable dimensions (Cacioppo, Gardner, \& Berntson, 1997; Diener, Smith, \& Fujita, 1995). Although the debate continues, research has reported the two-factor model fits the data better than the one-factor model despite strong inverse relationships between the positive and negative dimensions (Diener et al., 1995; Green, Goldman, \& Salovey, 1993).

Folkman and Moskowitz (2000) argued that the co-occurrence of positive emotions alongside negative emotions is plausible, particularly during difficult and stressful circumstances. In support of this notion, research conducted by Fredrickson and colleagues (e.g., Fredrickson, 2001; Fredrickson, Tugade, Waugh, \& Larkin, 2003) has demonstrated that positive and negative emotions co-occur during a given stressful period. To illustrate, employees might experience sadness (or even guilt) when they learn close friends are being terminated and, yet, quite happy and enthusiastic about the future when they discover their own jobs are secure.

Assuming positive and negative emotions are relatively distinct and co-occur, it is possible that both might account for unique variance in the prediction of job attitudes. Fisher (2000) reported, 
for example, that positive and negative emotions explained unique variance in three measures of job satisfaction. Her study suggests that both positive and negative emotions carry useful information with respect to job satisfaction. Thus, exploring both positive and negative emotions' unique contributions in predicting cynicism might provide insight with regard to which emotional states are related to employee cynicism. In line with Fisher's work that involved job satisfaction, we expected positive emotion to be negatively correlated with cynicism and negative emotion to be positively correlated with cynicism. Furthermore, we hypothesized both positive and negative emotions will explain unique variance in cynicism.

Hypothesis 3: Positive and negative emotions will each account for unique variance in the prediction of employee cynicism. Positive emotion will be negatively correlated with cynicism and negative emotion will be positively correlated with cynicism.

Reviews and empirical studies have reported on the significance of emotions in the workplace, often highlighting their role in mediating relationships between organizational conditions and job attitudes (see, for examples, Ashkanasy, Zerbe, \& Härtel, 2002; Brief \& Weiss, 2002). Coping research has similarly begun to investigate whether positive emotion mediates the relationship between psychological resilience and subjective well-being (e.g., Fredrickson et al., 2003; Tugade \& Fredrickson, 2004). In accordance with these views, we predict positive and negative emotions will also act as mediating mechanisms by which perceived supervisor support and psychological hardiness influence employee cynicism.

Perceived supervisor support, as defined earlier, refers to employees' beliefs regarding the extent to which their supervisors care about their well-being (Eisenberger et al., 2002). Whereas high levels of perceived supervisor support are expected to negatively correlate with employee cynicism, negative exchanges with one's supervisor are likely to reduce perceived support and, subsequently, positively correlate to cynicism (e.g., Leiter \& Harvie, 1997; Reichers, Wanous, \& Austin, 1997). Likewise, psychological hardiness is also expected to negatively correlate with employee cynicism, in part because hardy individuals are optimists, they construe job stressors as challenges capable of being mastered, and use more problem-focused coping strategies to deal with them (Maddi, 1999a). Moreover, as a result of their more positive outlook, hardy employees are more capable of finding positive meaning in their work in spite of any hardships faced as a result of a crisis. Hence, hardy employees are less likely to hold cynical beliefs towards their organization.

The expected relationships between perceived supervisor support and employee cynicism and hardiness and employee cynicism will, however, be indirect when employees' emotions are taken into account (Weiss \& Cropanzano, 1996). Emotions act as signals and, therefore, positive emotions suggest to the employee experiencing them that specific needs are being fulfilled. In turn, high levels of positive emotion are likely to create a more positive attitude towards an organization than low levels, whereas frustration and anger, for example, are expected to induce a more negative attitude towards an organization. Accordingly, AET (Weiss \& Cropanzano, 1996) holds that emotions are the mediating mechanism by which supervisory actions with supportive intent influence job attitudes, including employee cynicism. In a similar way, we predict hardiness proximally influences emotional experiences and distally influences their overall cynical attitude towards the organization through emotional mediation. Therefore:

Hypothesis 4: Positive emotion will mediate the relationships between perceived supervisor support, psychological hardiness and employee cynicism.

Hypothesis 5: Negative emotion will mediate the relationships between perceived supervisor support, psychological hardiness and employee cynicism. 


\section{Organizational Context}

The contextualization of organizational research has become increasingly relevant in recent years (Rousseau \& Fried, 2001). Accordingly, we felt it particularly important to provide a rich description of events occurring within the organization at the time of the study. The description below provides insights in the variety of emotions and related sentiments being experienced by company employees, many of whom provided data for the current study.

\section{Organizational Factors}

Approximately one year prior to the data collection, the European based medical technology company learned it was named as the defendant in a class-action lawsuit filed in the United States due to its manufacturing of a faulty product. In total, roughly 40000 products were recalled and some 30000 customers were presumed to be affected. Approximately 2 months before the current study was conducted, the company communicated to employees and shareholders it had reached a final agreement regarding the settlement arrangements. The company had agreed to pay approximately $\$ 1$ billion to settle thousands of lawsuits, the majority not covered by the company's insurance. Just weeks before the survey was set to begin, the company announced that it had changed its name and had appointed a new Chief Executive Officer. Days before survey administration, the company announced its plan to divest one-fourth of its core business units. In spite of the challenges confronting senior management, they were confident the company would survive the litigation settlement and, thus, wished to continue with the plans to initiate a longitudinal study to assess employees' opinions, attitudes, and emotions. It was therefore decided to roll out the questionnaire by inviting all employees located in the company's headquarters to complete the questionnaire; with subsequent administration dates set for the company's remaining employees. Data were collected from headquarter employees; however, the turmoil and massive change initiatives proved too much and all additional data collection dates were terminated. Approximately one year after the study, the company announced it was being acquired by a competitor.

\section{The Time Frame}

The data were collected in August 2002.

\section{Method}

\section{Participants and procedure}

The questionnaire was administered in German. One of the principal investigators whose first language is German translated the questionnaire into German. Then, a professional translator affiliated with the University of St. Gallen back-translated the questionnaire into English and we examined each item for translation error. Upon inspection, there were no instances where an item's meaning had significantly changed due to the translation. 
Every employee $(n=600)$ with a company e-mail address received an e-mail from the Chief Executive Officer (CEO) describing the purpose of the research and requesting all employees take the time necessary to complete the web-based survey. Respondents were promised complete anonymity. In total, 241 employees responded to the e-mail and completed the web-based survey. Of the employees who responded, 201 provided useable data on all study variables for a response rate of 34 per cent. Nearly two-thirds of the respondents were hourly employees (with no management responsibilities) and the remainder consisted of division managers ( 5 per cent), unit managers ( 8 per cent), departmental supervisors (10 per cent), or group leaders (14 per cent). The majority of employees indicated Marketing (25 per cent), Research and Development (23 per cent), or Operations (15 per cent) as their core function. Other functional areas included Human Resources, Information Technology, Finance, Sales, Logistics, or Quality Control. Although no formal comparisons of respondents and nonrespondents could be made, senior company leaders suggested the sample was representative of the larger population. Due to an agreement with the worker councils associated with the organization, the inclusion of demographic and other identification variables was not permitted.

\section{Measures}

Various response formats were originally used to develop the scales described below. To avoid confusing the respondents, all measures (unless otherwise noted) used a 7-cell response format ranging from 1 (never) to 7 (always). Past research has suggested relatively minor alterations to response formats do not affect their validity (Matell \& Jacoby, 1971). As part of the directions to respondents, when providing their ratings they were asked to refer to their feelings over the past few months. All items are included in the appendix.

\section{Perceived supervisor support}

Perceived supervisor support was measured with four items adapted from Eisenberger, Huntington, Hutchison, and Sowa's (1986) perceived organizational support (POS) measure. The items were modified in a similar manner as described in Rhoades, Eisenberger, and Armeli (2001). Due to internal language used by the company we inserted the word 'management,' whereas Rhoades et al. (2001) inserted the word 'supervisor' in place of 'organization.' This modification was strongly encouraged by senior level managers involved in the questionnaire development. In an attempt to ensure respondents referred to the support received from immediate supervisors, in the introductory directions on how to complete the survey as well as in directions provided in subsections, we asked respondents, when appropriate, to refer to their immediate superior or work group when providing their ratings. The four perceived supervisor support items were combined to form a single score (internal consistency $=0.80$ ).

\section{Psychological hardiness}

Hardiness was measured with six items (two per facet) based on the previous work of Bartone et al. (1989) and Maddi et al. (1999). When testing multifaceted constructs, including hardiness, researchers have opted to use a total score approach, whereby the subcomponents are combined in a linear fashion (Hull, Lehn, \& Tedlie, 1991). As a result, scores for each item were combined to produce a single hardiness score for each respondent (internal consistency $=0.76$ ).

\section{Emotion}

We assessed positive and negative emotions by adapting items from the Job Emotion Scale (JES; Fisher, 2000) and combining them with items developed specifically for this study. Two JES items, 'pleased' and 'content,' were judged to have excessive overlap with each other. Support for this 
conclusion is provided by their German translations. For instance, both items can be translated into German by using the adjective 'zufrieden.' Two other JES items, 'liking for someone or something' and 'enjoying something,' were eliminated from the present study. Although these two items could be translated into German, they were judged to be very different from the remaining JES items in terms of their phrasing. Consequently, 14 specific emotional states (7 positive and 7 negative) were chosen based on our rational judgment that the items (a) represented a variety of positive and negative emotions, and (b) were identified as having essentially the same meaning in both English and German. The directions in this section asked 'During the past few months, how often were these emotions experienced at work?'

Fisher (2000) investigated the factor structure of the emotion items using a principal components analysis with varimax rotation. Based on her results, Fisher concluded that emotion items clustered into positive and negative categories. In the present study, we also conducted a principal components analysis with varimax rotation to examine the factor structure of our 14 emotion items (cf. Fisher, 2000). Two factors were extracted based on eigenvalues-greater-than one (explaining 59.6 per cent of common variance), with a clear differentiation between positive and negative emotion factors. Results indicated five of the seven positive emotion items loaded strongly $(>0.60)$ on the positive emotion factor. One positive emotion item ('calm') loaded only on the negative emotion factor $(-0.50)$, and the other positive emotion item, 'content,' loaded on both the positive $(0.61)$ and negative $(-0.52)$ emotion factors. This latter item, content, was omitted from all further analyses. All negative emotion items loaded strongly $(>0.65)$ on the negative emotion factor with no cross-loadings. Scores for positive (five items; $\alpha=0.85$ ) and negative emotions (seven negative emotions and one reverse-scored positive emotion; $\alpha=0.89$ ) were created by averaging their respective items.

\section{Employee cynicism}

When the study was being conducted, we were unaware of existing, validated measures of employee cynicism. Cognizant of Dean et al.'s (1998) review as well as Wanous and colleagues' research (Reichers et al., 1997; Wanous et al., 2000), seven items were written by the present authors to assess employee cynicism. Consequently, it was important to examine the factor structure and correlates of our measure to provide some construct validity evidence. The seven cynicism items were therefore included in a subsequent study (i.e., in a different organization) also conducted by the authors. As part of the questionnaire used in this second project, we embedded a set of items for additional scale development purposes; included were the seven cynicism items. This sample consisted of a division of a multinational, manufacturing company. All participants $(n=660)$ were located in the United States and completed the questionnaire in English. Most were employees with no managerial responsibilities ( 65 per cent); were between 35 and 60 years old ( 75 per cent); and 73 per cent reported working for the company for more than 5 years.

Confirmatory factor analysis (CFA) using the full-information maximum likelihood (FIML) technique provided in AMOS 4.0 was used to test the dimensionality of our cynicism measure. FIML is superior to other imputation techniques as it gives unbiased estimates of means, variances, and other parameters (Arbuckle, 1996; Byrne, 2001). The comparative fit index (CFI), Tucker-Lewis Index (TLI), and the root mean square error of approximation (RMSEA) and its confidence interval were used in judging fit (Byrne, 2001). The model fitted to the data was a global, one-factor model. All fit indices indicated the unidimensional model was an acceptable fit, $\chi^{2}=83.2, d f=14, \mathrm{CFI}=0.994$, $\mathrm{TLI}=0.987$, RMSEA $=0.087$ and its 90 per cent confidence interval $(0.069,0.105)$. Furthermore, the factor loadings were significant and in the expected direction. Next, we examined the correlations between the cynicism measure and other measures included in this second project. We averaged employee responses to the seven cynicism items; a high score indicated a greater degree of cynicism (internal consistency $=0.83$ ). It was expected that cynicism would negatively correlate with 
transformational leadership (20 items, internal consistency $=0.97$; Bass \& Avolio, 2000), goal commitment (six items, internal consistency $=0.88$; Hollenbeck, Klein, O’Leary, \& Wright, 1989), and efficacy beliefs (six items, internal consistency $=0.79$; Riggs \& Knight, 1994). As expected, cynicism was negatively correlated with employee ratings of their managers' transformational leadership $(r=-0.46, p<0.01)$, self-reported commitment to goals $(r=-0.73, p<0.01)$, and efficacy beliefs $(r=-0.64, p<0.01)$. On the other hand, perceived external threats (four items, internal consistency $=0.60$, adapted from the environmental hostility scale by Slevin \& Covin, 1997) was expected to correlate to a lesser extent given that external threats are more distally related to cynicism perceptions. In support, external threats shared less than 1 per cent of the criterion space with cynicism $(r=0.08, p=\mathrm{ns})$. Although preliminary, these findings provide initial support for the reliability and validity of our cynicism measure.

A second CFA was then estimated using the employee responses from the principal sample (i.e., those employed by the organization facing the crisis). Once again, a global, one-factor cynicism model was fitted to the data. Results indicated that the fit indices were within or near acceptable ranges, $\chi^{2}=51.9, d f=14, \mathrm{CFI}=0.987, \mathrm{TLI}=0.974, \mathrm{RMSEA}=0.116$ and its 90 per cent confidence interval $(0.084,0.151)$ and all factor loadings were significant and in the expected direction. ${ }^{2}$ Consequently, employee responses to the seven cynicism items were combined to form a single score (internal consistency $=0.87$ ).

\section{Control variables}

The company was in the process of reorganizing certain business functions. Therefore, in all regression analyses, both department in which the respondent worked and hierarchical level were coded and used as control variables.

\section{Results}

Descriptive statistics, zero-order correlations, and coefficient alphas are reported in Table 1. Most of the correlations are consistent with expectations, however, a few warrant comment. For instance, the

Table 1. Means, standard deviations, alpha coefficients, and correlations

\begin{tabular}{|c|c|c|c|c|c|c|c|c|c|}
\hline Variable & $M$ & SD & 1 & 2 & 3 & 4 & 5 & 6 & 7 \\
\hline 1. Department ${ }^{\mathrm{a}}$ & 5.05 & 2.94 & - & & & & & & \\
\hline 2. Hierarchical level ${ }^{\mathrm{b}}$ & 5.18 & 1.35 & 0.11 & - & & & & & \\
\hline 3. Perceived supervisor support & 3.28 & 1.38 & -0.08 & $-0.29^{* *}$ & 0.80 & & & & \\
\hline 4. Psychological hardiness & 4.97 & 1.02 & -0.05 & -0.12 & $0.48^{* *}$ & 0.76 & & & \\
\hline 5. Positive emotion & 4.04 & 1.20 & $-0.15^{*}$ & $-0.21^{* *}$ & $0.52^{* *}$ & $0.50^{* *}$ & 0.85 & & \\
\hline 6. Negative emotion & 3.94 & 1.31 & 0.03 & $0.17^{*}$ & $-0.50^{* *}$ & $-0.39^{* *}$ & $-0.66^{* *}$ & 0.89 & \\
\hline 7. Employee cynicism & 3.83 & 0.98 & 0.06 & $0.27^{* *}$ & $-0.50^{* *}$ & $-0.46^{* *}$ & $-0.69^{* *}$ & $0.73^{* *}$ & 0.87 \\
\hline
\end{tabular}

Note: $N=201$. Cronbach alpha estimates are on the diagonal.

${ }^{\mathrm{a}} 1=$ Marketing, $2=\mathrm{HR}, 3=\mathrm{IT}, 4=$ Finance, $5=$ Sales, $6=$ Logistics, $7=\mathrm{R} \& \mathrm{D}, 8=$ Quality, $9=$ Quality and Clinicals.

${ }^{\mathrm{b}} 1=$ Corporate executive, $2=$ Senior level manager, $3=$ Middle-manager, $4=$ Low-level manager, $5=$ Team leader, $6=$ No managerial responsibility.

${ }^{*} p<0.05$ (two-tailed).

${ }^{* *} p<0.01$ (two-tailed).

\footnotetext{
${ }^{2}$ A principal components analysis with varimax rotation further suggested the employee cynicism measure was unidimensional. One factor was extracted based on eigenvalues-greater-than one, explaining 56.2 per cent of the common variance (factor loadings ranged from 0.45 to 0.84$)$.
} 
correlation between positive and negative emotions was $r=-0.66$. This strong inverse correlation between the two emotion variables was not entirely unexpected, as comparable levels of association have been reported in earlier studies (e.g., Fredrickson et al., 2003). Moreover, the average correlation between positive emotion, negative emotion, and employee cynicism was $|0.69|$. Although this suggests a considerable amount of overlap among the three constructs, it by no means implies that the measures are indicators of the same construct (cf. Mathieu \& Farr, 1991). Nonetheless, we believed it important to investigate the empirical distinctiveness of positive and negative emotions and employee cynicism. Therefore, five confirmatory factor analysis models were specified following the procedures outlined by Chen, Gully, and Eden (2001). The first analysis tested a three-factor measurement model that allowed the factors to freely correlate. Fit indices suggested this model was a good fit to the data, $\chi^{2}=296.7, d f=167, \mathrm{CFI}=0.986, \mathrm{TLI}=0.982, \mathrm{RMSEA}=0.062$ and its 90 per cent confidence interval $(0.051,0.074)$. Next, we tested four alternative models: (a) three two-factor models (in each case one correlation between two factors was set at 1.0) and (b) a one-factor model in which all three factors were set to correlate at 1.0. Results from the chi-square difference tests indicated each alternative model with unity constraints was a significantly worse fitting model. Thus, despite the correlations between the measures, on the basis of both theoretical and empirical grounds, we concluded that positive and negative emotions and employee cynicism are distinct constructs.

\section{Hypotheses Tests}

Hierarchical regression was used to test the study's hypotheses. The control variables were entered in the first hierarchical step in each regression model. Hypotheses $1 a$ and $l b$ predicted that perceived supervisor support would be positively correlated with positive emotion and negatively correlated with negative emotion. Hypotheses $2 a$ and $2 b$ predicted similar relationships between psychological hardiness and positive and negative emotions. Therefore, we regressed positive and negative emotions on perceived supervisor support and psychological hardiness (see Table 2). Shown in step two of the regression models, the individual beta weights indicated both perceived supervisor support $(\beta=0.35$, $p<0.001)$ and hardiness $(\beta=0.32, p<0.001)$ positively correlated with positive emotion and

Table 2. Mediators regressed on perceived supervisor support and psychological hardiness

\begin{tabular}{|c|c|c|c|c|}
\hline \multirow[b]{3}{*}{ Variable } & \multicolumn{4}{|c|}{ Criterion } \\
\hline & \multicolumn{2}{|c|}{ Positive emotion } & \multicolumn{2}{|c|}{ Negative emotion } \\
\hline & Step 1 & Step 2 & Step 1 & Step 2 \\
\hline \multicolumn{5}{|l|}{ Controls: } \\
\hline Department & -0.12 & -0.10 & 0.01 & -0.02 \\
\hline Hierarchical level & $-0.20^{* *}$ & -0.06 & $0.17^{*}$ & 0.04 \\
\hline \multicolumn{5}{|l|}{ Predictors: } \\
\hline Perceived supervisor support & & $0.35^{* * *}$ & & $-0.40^{* * *}$ \\
\hline Psychological hardiness & & $0.32^{* * *}$ & & $-0.19^{* *}$ \\
\hline$\Delta R^{2}$ & & 0.31 & & 0.25 \\
\hline Overall Adjusted $R^{2}$ & 0.05 & 0.36 & 0.02 & 0.27 \\
\hline Overall $F$ & $6.1^{* *}$ & $30.0^{* * *}$ & $3.1^{*}$ & $19.0^{* * *}$ \\
\hline
\end{tabular}

Note: $N=201$. Entries are standardized beta weights.

${ }^{*} p<0.05$ (two-tailed).

${ }^{* *} p<0.01$ (two-tailed).

${ }^{* * *} p<0.001$ (two-tailed). 
negatively correlated with negative emotion, $(\beta=-0.40, p<0.001)$ and $(\beta=-0.19, p<0.01)$, respectively. Thus, Hypotheses $1 a-1 b$ and $2 a-2 b$ were supported. Furthermore, the results satisfy one of the four requirements needed to support our mediation hypotheses (cf. Kenny, Kashy, \& Bolger, 1998).

Hypothesis 3 predicted both positive and negative emotions would account for unique variance in employee cynicism. Employing usefulness analyses (Cohen \& Cohen, 1983), results indicated positive emotion accounted for unique variance in employee cynicism $\left(\Delta R^{2}=0.04, p<0.001\right)$ beyond that explained by the controls, both predictor variables, and negative emotion. Negative emotion similarly accounted for unique variance in employee cynicism $\left(\Delta R^{2}=0.11, p<0.001\right)$ beyond that explained by the controls, both predictors, and positive emotion. Consequently, Hypothesis 3 received support and a second requirement for mediation, that is, the mediating variables must correlate with the criterion (Kenny et al., 1998) was satisfied.

Hypothesis 4 stated that positive emotion would mediate the relationship between perceived supervisor support and employee cynicism and hardiness and employee cynicism. Similarly, Hypothesis 5 stated that negative emotion would mediate the relationships between perceived supervisor support and employee cynicism and hardiness and employee cynicism. Implicit in Hypotheses 4-5 is the expectation that both perceived supervisor support and hardiness are associated with employee cynicism (cf. Kenny et al., 1998). Shown in Table 3, when simultaneously entered in the second hierarchical step (see step 2), the predictors explained unique variance in employee cynicism $\left(\Delta R^{2}=0.26, p<0.001\right)$ and both perceived supervisor support $(\beta=-0.32, p<0.001)$ and hardiness $(\beta=-0.29, p<0.001)$ were significant and in the expected direction; satisfying the third requirement for mediation.

In order to fully support Hypotheses 4-5, the relationships between the predictor variables (perceived supervisor support and hardiness) and employee cynicism must disappear when the emotion variables are entered in a final hierarchical step. Reported in Table 3, emotions accounted for unique variance in employee cynicism $\left(\Delta R^{2}=0.30, p<0.001\right)$ over and above the 32 per cent previously explained by the controls (step 1) and perceived supervisor support and hardiness (step 2). Also shown

Table 3. Mediation of the relationship of perceived supervisor support and hardiness with employee cynicism by positive and negative emotions

\begin{tabular}{|c|c|c|c|}
\hline \multirow[b]{2}{*}{ Variable } & \multicolumn{3}{|c|}{ Employee cynicism } \\
\hline & Step 1 & Step 2 & Step 3 \\
\hline \multicolumn{4}{|l|}{ Controls: } \\
\hline Department & 0.04 & 0.01 & -0.01 \\
\hline Hierarchical level & $0.26^{* * *}$ & $0.14^{*}$ & $0.10^{*}$ \\
\hline \multicolumn{4}{|l|}{ Predictors: } \\
\hline Perceived supervisor support & & $-0.32^{* * *}$ & -0.04 \\
\hline Psychological hardiness & & $-0.29^{* * *}$ & -0.10 \\
\hline \multicolumn{4}{|l|}{ Mediators: } \\
\hline Positive emotion & & & $-0.29^{* * *}$ \\
\hline Negative emotion & & & $0.46^{* * *}$ \\
\hline$\Delta R^{2}$ & & 0.26 & 0.30 \\
\hline Overall adjusted $R^{2}$ & 0.06 & 0.32 & 0.62 \\
\hline Overall $F$ & $7.7^{* *}$ & $24.0^{* * *}$ & $54.5^{* * *}$ \\
\hline
\end{tabular}

Note: $N=201$. Entries are standardized beta weights.

${ }^{*} p<0.05$ (two-tailed).

${ }^{* *} p<0.01$ (two-tailed).

${ }^{* * * *} p<0.001$ (two-tailed). 
in Table 3 (step 3), beta weights for perceived supervisor support $(\beta=-0.04, p=n s)$ and hardiness $(\beta=-0.10, p=n s)$ were nonsignificant, indicating emotions fully mediated the relations between perceived supervisor support and hardiness and employee cynicism. Finally, an inspection of the variance inflation factor scores (VIFs) indicated that there were no instances of multicollinearity among any of the variables (largest VIF $=2.14$ ). Consequently, Hypotheses 4 and 5 were supported.

\section{Discussion}

As noted at the outset, much work remains to be done to fully understand and better manage cynicism in organizations. To date, most empirical studies have focused on the specific targets of cynicism (e.g., organizational change; Wanous et al., 2000), or focused solely on the negative consequences related to employee cynicism (Brandes et al., 1999). With this in mind, the present study makes two primary contributions to the literature. First, by integrating the general predictions made by AET (Weiss \& Cropanzano, 1996) with Andersson's (1996) conceptual model of employee cynicism, we have presented a theory-driven model that takes into account two salient individual-level predictors of employee cynicism. This perspective provides yet another explanation for the antecedents of employee cynicism, complementing past research which has predominantly used psychological contract breach as its theoretical base (e.g., Johnson \& O'Leary-Kelly, 2003). Second, by examining positive and negative emotion as mediators, we have begun to elucidate exactly how and why individual perceptions of supervisor support and personal characteristics impact cynicism development. Given that high levels of employee cynicism are known to have a detrimental effect on key organizational and individuallevel outcomes (Johnson \& O'Leary-Kelly, 2003; Treadway et al., 2004), explaining any significant relationships, particularly those that reduce cynical reactions, seem particularly noteworthy and might even help to provide better ways to manage the phenomenon (Dean et al., 1998).

Overall, the current research provides initial support for our proposed mediation model, and for the efficacy of an AET-based model of employee cynicism. The regression analyses supported our predictions, as we found perceived supervisor support and hardiness to have indirect relationships with cynicism through employees' affective reactions. In line with Weiss and Cropanzano (1996), our results suggest that rather than being an end-state outcome, emotions serve as a generative mechanism or conduit that transmits the effects of supervisor support and hardiness to employee cynicism. Hence, we expect AET (Weiss \& Cropanzano, 1996) will benefit future cynicism studies as it provides researchers with a useful theoretical framework to integrate propositions from the psychological contract (Rousseau, 1989; Rousseau \& McLean Parks, 1993) and emotion (Brief \& Weiss, 2002) and coping (Perrewé \& Zellars, 1999) literatures. Although these perspectives reflect distinct literature streams, Weiss and Cropanzano's AET theory offers a comprehensive framework that researchers may draw on to help illuminate the train of events that lead to cynical responses and subsequent job outcomes. For example, AET proposes that affective experiences contribute to the explanation of job attitudes (e.g., employee cynicism) and, eventually, judgment-driven behaviors such as decisions to quit an organization. If future cynicism research verifies and extends the current study's findings, substantial implications for an AET-based model of employee cynicism may be realized.

The support for Hypothesis 3, that both positive and negative emotion accounted for unique variance in employee cynicism, also holds implications for future studies on emotion. For instance, although causal attributions by employees and related emotions may not be directly controllable (e.g., Perrewé \& Zellars, 1999), the organizational events that trigger the attribution process are amenable to intervention. Thus, we share Fisher's (2000) viewpoint, in that future studies should consider a twopronged approach whereby researchers identify specific events hypothesized to create positive emotion 
(e.g., uplifts) as well as reduce the onset of negative emotion (e.g., hassles). Furthermore, emotions carry useful information as they inform individuals about what is good and bad in the environment and, in turn, these emotional experiences are known to influence job attitudes. Consistent with cynicism theory (Andersson, 1996; Dean et al., 1998), the present results indicated that employees' negative emotions were a more useful predictor (explaining 2.75 times more variance than did positive emotion) of the cynicism attitude. Taken together with Fisher's (2000) results, it appears as though certain job attitudes may be differentially related to positive and negative emotions. Accordingly, we look forward to future research that more fully considers the likelihood of differential relations between emotions and job attitudes and/or behavioral outcomes (affect-driven or judgment-driven).

To the authors' knowledge, this is the first study to report such relationships in a field study of an actual organization in crisis. To this end, the organizational setting provided us with a unique context to study organizational behavior, particularly the antecedents of employee cynicism as the study sample was most likely experiencing an array of emotions and sentiments relating to cynicism (e.g., lack of organizational integrity). Consider, for example, that employee cynicism has been suggested to surface when there are disparities between an employee's fundamental expectations and reality. On this basis, researchers have generally presumed that psychological contract breach is cynicism's principal determinant (Andersson, 1996). In one of the first tests of Andersson's (1996) predictions, Johnson and O'Leary-Kelly (2003) found that cynicism partially mediated the psychological contract breach-job attitudes relationship and cynicism fully mediated the psychological contract breach-emotional exhaustion relationship. Hence, cynicism has been suggested to be a defensive response in the sense that it shields individuals against feeling strong emotions which are psychologically threatening (e.g., Kalimo, Taris, \& Schaufeli, 2003).

Our study results, however, point to a slightly different understanding with regard to the influencing sources of cynical attitudes. Specifically, workplace emotions were found to be important intervening variables between aspects of the employees' work environment, their personal characteristics, and cynicism. In view of the strong relationships we reported between emotional reactions and employee cynicism $\left(\Delta R^{2}=0.30\right)$, past research may have omitted a potentially important explanatory variable. In support of this idea, Muchinsky (2000, p. 805) stated that workplace emotions have both theoretical and practical appeal because they lie at the heart of the human experience, being manifest in a context that consumes a majority of a typical employee's energies — one's job. It would be interesting, therefore, to replicate Johnson and O'Leary-Kelly's (2003) study but with the inclusion of emotion variables as additional mediators. As suggested by an anonymous reviewer, such a study might also consider assessing individuals' discrete emotions rather than the widely used, more general positive and negative emotion dichotomy. For example, anger, worry, or frustration may each contribute to increased levels of psychological withdrawal and cynicism (Perrewé \& Zellars, 1999). Similarly, guilt may help to explain why some downsizing survivors have reported elevated levels of cynicism (Kalimo et al., 2003) and decreased levels of job satisfaction and reduced organizational commitment (e.g., Davy, Kinicki, \& Scheck, 1997). Thus, future research that investigates the role of discrete emotions could provide an informative and more specific understanding of the kinds of feelings that that might be mediating the relationships reported in our study.

\section{Limitations of the research}

First, our analyses were based on a sample with specific geographic and contextual factors, both characteristics that limit the generalizability of the results. Second, the data were cross-sectional and could not be used to test causality. Initially, a longitudinal design was planned but a number of contextual factors did not permit its execution. Although the mediation effects we reported are 
consistent with the causal relationships implied, future studies should use longitudinal designs in order to firmly establish the causal paths. Third, because the data for this study were collected using selfreports, concern may arise as to whether the results are simply methodological artifacts. Several points should be made in this regard. First, some researchers have indicated the bias caused by self-report data might be overstated (Crampton \& Wagner, 1994; Harrison, McLaughlin, \& Coalter, 1996; Spector, 1994). Second, common-method bias is less of a concern for our hierarchical regression analyses because we were interested in accounting for unique variance. In this instance, the presence of common-method bias would make it more difficult to find support for the study's hypotheses. Third, we followed a procedure outlined by Williams, Cote, and Buckley (1989) to empirically examine the extent to which our measures were influenced by common-method variance. We first estimated the fit of a five-factor measurement model that fixed item indicators to their respective factors (i.e., perceived supervisor support, hardiness, positive emotion, negative emotion, or employee cynicism) and allowed the latent constructs to freely covary. This measurement model was an excellent fit to the data, $\chi^{2}=683.9, d f=395, \mathrm{CFI}=0.979, \mathrm{TLI}=0.976$, and $\mathrm{RMSEA}=0.060$ and its 90 per cent confidence interval $(0.053,0.068)$, which demonstrates that the five measures, as assessed, are empirically distinct. We then included a "same source" factor to each item indicator of all five latent constructs and reestimated the model. The chi-square difference test between the two models suggests that a samesource factor is present $\left(\Delta \chi^{2}=141.3, \Delta d f=30, p<0.01\right)$. However, a comparison of the latent correlations $(\phi)$ between constructs in both models indicated that the method bias was minimal, as the correlations in both models were nearly identical (average $\Delta \phi=-0.02$ ). Of the 10 correlations, four were inflated and six were attenuated. Based on the preceding evidence, we concluded that the measures were independent constructs and that the study's findings were not the sole result of commonmethod bias.

Finally, an interesting feature of the study was the context in which it took place and, yet, none of the measures used explicitly refer to this event. This can be perceived as a limitation given that we were unable to rule out competing explanations such as the possibility that perceived contract violations contributed to employee cynicism. These types of measures, despite our attempt to include them, were deemed by the host organization as being unsuitable due to the sensitivity surrounding the crisis situation. Thus, this limitation should also be considered when interpreting our findings.

\section{Study implications}

It is well known that organizational change initiatives can have adverse effects on employees (Pfeffer, 1998; Sverke, Hellgren, \& Näswall, 2002). One reason to expect detrimental effects is Rousseau's (1996) argument that an individual's need for information dramatically increases because of the uncertainties associated with change. Information and support, however, may or may not be available (Rousseau, 1996). From employees' perspective, supervisors are responsible for providing information and support because they are perceived to be the principal agents of the organization and, therefore, the main channel through which information flows. In this regard, Holt, Self, Thal, and Lo (2003) distinguished between senior leaders who initiate the change and lower level supervisors who are perceived as change agents responsible for communicating the change and providing information and assistance to employees. Hence, the attribution that they will be supported and cared for by their supervisor, especially during times of change, will likely result in employees feeling more positive, and, subsequently, less cynical.

Whereas information and support provided by supervisors helps to satisfy employees' needs and, therefore, yields positive emotions; low supervisor support is perceived to threaten employees' needs, which yields negative emotions (cf. Weiss \& Cropanzano, 1996). In supervisor-employee interactions 
involving low supervisor support, it is likely that the quantity and quality of information made available to employees actually declined (Rousseau, 1996). Wanous et al. (2000) reported employees were inclined to fill these information gaps with explanations that the company must 'not be doing well, or I would have heard something' or the company 'must be experiencing serious problems.' Employees who develop such explanations are much more likely to experience negative emotions. Supporting Wanous et al., we found low levels of perceived supervisor support were associated with negative emotions, including frustration, unhappiness, and helplessness. These results also highlight middle manager's ability to affect employees' emotional experiences during change (Huy, 2002).

We also found that the higher an individual's hardiness, the more positive the person was feeling and, subsequently, the less likely the individual held a cynical attitude towards the organization. Referring back to the three hardiness components, when confronted with the crisis, hardy employees were probably more committed to finding meaningful purpose in their work, believed that they could influence their surroundings and the outcome of events, and believed that they could learn and grow from the challenges they were facing (Bonanno, 2004). Considered together, this finding is interesting given that organizations can develop or enhance hardiness mechanisms through training (Khoshaba \& Maddi, 2001; Maddi, Kahn, \& Maddi, 1998). Such training might be an invaluable developmental aid for individuals of organizations who are at risk of experiencing major stressors because of their occupations or organizational circumstances.

\section{Conclusion}

In closing, employee cynicism is typically viewed as a defensive response in the sense that people develop cynicism as a shield against feeling strong emotions which are psychologically threatening. In other words, cynicism allows the person to distance themselves and remain somewhat aloof. Our findings suggest, however, this may not be the case. Results showed there were strong emotions behind the cynicism response, i.e., the stronger the negative (positive) emotions the more (less) cynical the person. Thus, our findings suggest that employees' emotional responses are a crucial part of the process by which the cynicism attitude forms and, therefore, imply there is more than just a cognitive interpretation of the workplace events purported to foster cynicism in organizations.

\section{Acknowledgements}

The authors thank Achilles Armenakis, Arthur Bedeian, Boas Shamir, and Frank Walter for vetting earlier drafts of this manuscript, a previous version of which appears in the 2004 Academy of Management Proceedings. We also gratefully acknowledge the assistance of Hubert Feild. Finally, we express our appreciation to Raymond Noe and the three anonymous reviewers for their constructive contributions to our manuscript.

\section{Author biographies}

Michael S. Cole is a Senior Research Fellow and Lecturer in the Institute for Leadership and Human Resource Management at the University of St. Gallen, in Switzerland. He earned his PhD from the Department of Management at Auburn University. His research interests involve multilevel theories of 
organizational behavior. In particular, he is interested in how organizational contextual factors influence employees' attachments to organizations.

Heike Bruch is a Professor of Leadership and the Director of the Institute for Leadership and Human Resource Management at the University of St. Gallen, in Switzerland. Prior to accepting the Professor of Leadership position, she worked at the London Business School, first as a Visiting Scholar and later as a Senior Research Fellow in Strategic Leadership. Her research interests focus on international and strategic leadership. The focal points of her more recent work include managers' action and volition as well as organizational energy and leadership strategies.

Bernd Vogel is a Senior Research Fellow and Lecturer in the Institute of Leadership and Human Resource Management at the University of St. Gallen, in Switzerland. He is also a project leader in the Organizational Energy Program (OEP). In the OEP, he investigates how organizational energy emerges and how it can be influenced. His research also focuses on leadership and collective emotions in organizations. He received his PhD from the University of Hanover, Germany.

\section{References}

Andersson, L. M. (1996). Employee cynicism: An examination using a contract violation framework. Human Relations, 49, 1395-1415.

Andersson, L. M., \& Bateman, T. S. (1997). Cynicism in the workplace: Some causes and effects. Journal of Organizational Behavior, 18, 449-469.

Arbuckle, J. L. (1996). Full information estimation in the presence of missing data. In G. A. Marcoulides, \& R. E. Schumaker (Eds.), Advanced structural equation modeling: Issues and techniques (pp. 243-277). Mahwah, NJ: Erlbaum.

Ashkanasy, N. M., \& Daus, C. S. (2002). Emotion in the workplace: The new challenge for managers. Academy of Management Executive, 16, 76-86.

Ashkanasy, N. M., Zerbe, W. J., \& Härtel, C. E. J., (Eds.). (2002). Managing emotions in the workplace. New York: M. E. Sharpe.

Bartone, P. T., Ursano, R. J., Wright, K. M., \& Ingraham, L. H. (1989). The impact of a military disaster on the health of assistance workers. The Journal of Nervous and Mental Disease, 177, 317-328.

Bass, B. M., \& Avolio, B. J. (2000). Multifactor Leadership Questionnaire: Technical report, leader form, rater form, and scoring key for MLQ form 5x-short (2nd ed.). Redwood City, CA: Mindgarden.

Bedeian, A. G. (in press). Even if the tower is 'ivory,' it isn't 'white': Understanding the consequences of faculty cynicism. Academy of Management Learning and Education.

Brandes, P., Dharwadkar, R., \& Dean, J. W. (1999). Does organizational cynicism matter?: Employee and supervisor perspectives on work outcomes. Eastern Academy of Management best papers proceedings, 150 153.

Bommer, W. H., Rich, G. A., \& Rubin, R. S. (2005). Changing attitudes about change: Longitudinal effects of transformational leader behavior on employee cynicism about organizational change. Journal of Organizational Behavior, 26, 733-753.

Bonanno, G. A. (2004). Loss, trauma, and human resilience: Have we underestimated the human capacity to thrive after extremely aversive events? American Psychologist, 59, 20-28.

Brief, A. P., \& Weiss, H. M. (2002). Organizational behavior: Affect in the workplace. Annual Review of Psychology, 53, 279-307.

Britt, T. W., Adler, A. B., \& Bartone, P. T. (2001). Deriving benefits from stressful events: The role of engagement in meaningful work and hardiness. Journal of Occupational Health Psychology, 6, 53-63.

Byrne, B. M. (2001). Structural equation modeling with AMOS: Basic concepts, applications, and programming. Mahwah, NJ: Erlbaum.

Cacioppo, J. T., Gardner, W. L., \& Berntson, G. G. (1997). Beyond bipolar conceptualizations and measures: The case of attitudes and evaluative space. Personality and Social Psychology Review, 1, 3-25. 
Chen, G., Gully, S. M., \& Eden, D. (2001). Validation of a new general self-efficacy scale. Organizational Research Methods, 4, 62-83.

Cohen, J., \& Cohen, P. (1983). Applied multiple regression/correlation analysis for the behavioral sciences. Hillsdale, NJ: Erlbaum.

Crampton, S. M., \& Wagner, J. A., III. (1994). Percept-percept inflation in microorganizational research: An investigation of prevalence and effect. Journal of Applied Psychology, 79, 67-76.

Dasborough, M. T., \& Ashkanasy, N. M. (2002). Emotion and attribution of intentionality in leader-member relationships. The Leadership Quarterly, 13, 615-635.

Davy, J. A., Kinicki, A. J., \& Scheck, C. L. (1997). A test of job security's direct and mediated effects on withdrawal cognitions. Journal of Organizational Behavior, 18, 323-349.

Dean, J. W., Brandes, P., \& Dharwadkar, R. (1998). Organizational cynicism. Academy of Management Review, 23, 341-352.

Diener, E., Smith, H., \& Fujita, F. (1995). The personality structure of affect. Journal of Personality and Social Psychology, 69, 130-141.

Eisenberger, R., Huntington, R., Hutchison, S., \& Sowa, D. (1986). Perceived organizational support. Journal of Applied Psychology, 71, 500-507.

Eisenberger, R., Stinglhamber, F., Vandenberghe, C., Sucharski, I. L., \& Rhoades, L. (2002). Perceived supervisor support: Contributions to perceived organizational support and employee retention. Journal of Applied Psychology, 87, 565-573.

Ferris, G. R., Bhawuk, D. P. S., Fedor, D. F., \& Judge, T. A. (1995). Organizational politics and citizenship: Attributions of intentionality and construct definition. In M. J. Martinko (Ed.), Advances in attribution theory: An organizational perspective (pp. 231-252). Delray Beach, FL: St. Lucie Press.

Fisher, C. D. (2000). Mood and emotions while working: Missing pieces of job satisfaction? Journal of Organizational Behavior, 21, 185-202.

Fisher, C. D. (2002). Antecedents and consequences of real-time affective reactions at work. Motivation and Emotion, 26, 3-30.

Florian, V., Mikulincer, M., \& Taubman, O. (1995). Does hardiness contribute to mental health during a stressful real-life situation? The roles of appraisal and coping. Journal of Personality \& Social Psychology, 68, 687-695.

Folkman, S., \& Moskowitz, J. T. (2000). Positive affect and the other side of coping. American Psychologist, 55, 647-654.

Fredrickson, B. L. (2001). The role of positive emotions in positive psychology. American Psychologist, 56, 218 226.

Fredrickson, B. L., Tugade, M. M., Waugh, C. E., \& Larkin, G. R. (2003). What good are positive emotions in crises?: A prospective study of resilience and emotions following the terrorist attacks on the Unites States on September 11th, 2001. Journal of Personality and Social Psychology, 84, 365-376.

George, J. M. (1996). Trait and state affect. In K. R. Murphy (Ed.), Individual differences and behavior in organizations (pp. 145-171). San Francisco: Jossey-Bass.

George, J. M., Reed, T. F., Ballard, K. A., Colin, J., \& Fielding, J. (1993). Contact with AIDS patients as a source of work-related distress: Effects of organizational and social support. Academy of Management Journal, 36, 157171.

Green, D. P., Goldman, S., \& Salovey, P. (1993). Measurement error masks bipolarity in affect ratings. Journal of Personality and Social Psychology, 64, 1029-1041.

Green, D. P., Salovey, P., \& Truax, K. M. (1999). Static, dynamic, and causative bipolarity of affect. Journal of Personality and Social Psychology, 76, 856-867.

Harrison, D. A., McLaughlin, M. E., \& Coalter, T. M. (1996). Context, cognition, and common method variance: Psychometric and verbal protocol evidence. Organizational Behavior and Human Decision Processes, 68, 246261.

Hollenbeck, J. R., Klein, H. J., O'Leary, A. M., \& Wright, P. M. (1989). Investigation of the construct validity of a self-report measure of goal commitment. Journal of Applied Psychology, 74, 951-956.

Holt, D. T., Self, D. R., Thal, A. E., \& Lo, S. W. (2003). Facilitating organizational change: A test of leadership strategies. Leadership and Organizational Development Journal, 24, 262-272.

Hull, J. G., Lehn, D. A., \& Tedlie, J. C. (1991). A general approach to testing multifaceted personality constructs. Journal of Personality and Social Psychology, 61, 932-945.

Humphrey, R. H. (2002). The many faces of emotional leadership. The Leadership Quarterly, 13, $493-504$.

Huy, Q. N. (2002). Emotional balancing of organizational continuity and radical change: The contribution of middle managers. Administrative Science Quarterly, 47, 31-69. 
Johnson, J. L., \& O'Leary-Kelly, A. M. (2003). The effects of psychological contract breach and organizational cynicism: Not all social exchange violations are created equal. Journal of Organizational Behavior, 24, 627647.

Kalimo, R., Taris, T. W., \& Schaufeli, W. B. (2003). The effects of past and anticipated future downsizing on survivor well-being: An equity perspective. Journal of Occupational Health Psychology, 8, 91-109.

Kanter, D. L., \& Mirvis, P. H. (1989). The cynical Americans. San Francisco: Jossey-Bass.

Kenny, D. A., Kashy, D. A., \& Bolger, N. (1998). Data analysis in social psychology. In D. T. Gilbert, S. T. Fiske, \& G. Lindzey (Eds.), The handbook of social psychology (4th ed., pp. 233-265). Boston: McGraw-Hill.

Khoshaba, D. M., \& Maddi, S. R. (2001). HardiTraining (4th ed.). Newport Beach, CA: Hardiness Institute.

Kobasa, S. C. (1979). Stressful life events, personality and health: An inquiry into hardiness. Journal of Personality and Social Psychology, 37, 1-11.

Kobasa, S. C., Maddi, S. R., \& Kahn, S. (1982). Hardiness and health: A prospective study. Journal of Personality and Social Psychology, 42, 168-177.

Lazarus, R. S. (1991). Emotion and adaptation. New York: Oxford University Press.

Leiter, M., P., \& Harvie, P. (1997). Correspondence of supervisor and subordinate perspectives during major organizational change. Journal of Occupational Health Psychology, 2, 343-352.

Maddi, S. R. (1999a). Comments on trends in hardiness research and theorizing. Consulting Psychology Journal: Practice \& Research, 51, 67-71.

Maddi, S. R. (1999b). The personality construct of hardiness, I: Effects on experiencing, coping, and strain. Consulting Psychology Journal: Practice \& Research, 51, 83-94.

Maddi, S. R. (2005). On hardiness and other pathways to resilience. American Psychologist, 60, 261-262.

Maddi, S. R. \& Kobasa, S. C. (1981). Existential personality theory. In H. I. Day (Ed.), Advances in intrinsic motivation and aesthetics (pp. 299-321). New York: Plenum.

Maddi, S. R., Kahn, S., \& Maddi, K. L. (1998). The effectiveness of hardiness training. Consulting Psychology Journal: Practice \& Research, 50, 78-86.

Maddi, S. R., Khoshaba, D. M., \& Pammenter, A. (1999). The hardy organization: Success by turning change to advantage. Consulting Psychology Journal: Practice and Research, 51, 117-124.

Matell, M. S., \& Jacoby, J. (1971). Is there an optimal number of alternatives for Likert scale items? Educational and Psychological Measurement, 31, 657-674.

Mathieu, J. E., \& Farr, J. L. (1991). Further evidence for the discriminant validity of measures of organizational commitment, job involvement, and job satisfaction. Journal of Applied Psychology, 76, 127-133.

McColl-Kennedy, J. R., \& Anderson, R. D. (2002). Impact of leadership style and emotions on subordinate performance. The Leadership Quarterly, 13, 545-559.

Muchinsky, P. M. (2000). Emotions in the workplace: The neglect of organizational behavior. Journal of Organizational Behavior, 21, 801-805.

Pescosolido, A. T. (2002). Emergent leaders as managers of group emotion. The Leadership Quarterly, 13, 583599.

Perrewé, P. L., \& Zellars, K. L. (1999). An examination of attributions and emotions in the transactional approach to the organizational stress process. Journal of Organizational Behavior, 20, 739-752.

Pfeffer, J. (1998). The human equation: Building profits by putting people first. Boston: Harvard University Press.

Reichers, A. E., Wanous, J. P., \& Austin, J. T. (1997). Understanding and managing cynicism about organizational change. Academy of Management Executive, 11, 48-59.

Rhoades, L., \& Eisenberger, R. (2002). Perceived organizational support: A review of the literature. Journal of Applied Psychology, 87, 698-714.

Rhoades, L., Eisenberger, R., \& Armeli, S. (2001). Affective commitment to the organization: The contribution of perceived organizational support. Journal of Applied Psychology, 86, 825-836.

Rhonewalt, F., \& Agustsdottir, S. (1984). On the relationship of hardiness to the Type A behavior pattern: Perception of life events versus coping with life events. Journal of Research in Personality, 18, $212-223$.

Riggs, M. L., \& Knight, P. A. (1994). The impact of perceived group success - failure on motivational beliefs and attitudes: A causal study. Journal of Applied Psychology, 79, 755-766.

Rousseau, D. M. (1989). Psychological and implied contracts in organizations. Employee Rights and Responsibilities Journal, 2, 121-139.

Rousseau, D. M. (1996). Changing the deal while keeping the people. Academy of Management Executive, 10, $50-61$.

Rousseau, D. M., \& Fried, Y. (2001). Location, location, location: Contextualizing organizational research. Journal of Organizational Behavior, 22, 1-13. 
Rousseau, D. M., \& McLean Parks, J. (1993). The contracts of individuals and organizations. Research in Organizational Behavior, 15, 1-47.

Russell, J. A., \& Carroll, J. M. (1999). On the bipolarity of positive and negative affect. Psychological Bulletin, $125,3-30$.

Sagie, A., \& Koslowsky, M. (1994). Organizational attitudes and behaviors as a function of participation in strategic and tactical change decisions: An application of path-goal theory. Journal of Organizational Behavior, $15,37-47$.

Slevin, D. P., \& Covin, J. G. (1997). Strategy formation patterns, performance, and the significance of context. Journal of Management, 23, 189-209.

Spector, P. E. (1994). Using self-report questionnaires in OB research: A comment on the use of a controversial method. Journal of Organizational Behavior, 15, 385-392.

Sverke, M., Hellgren, J., \& Näswall, K. (2002). No security: A meta-analysis and review of job insecurity and its consequences. Journal of Occupational Health Psychology, 7, 242-264.

Treadway, D. C., Hochwater, W. A., Ferris, G. R., Kacmar, C. J., Douglas, C., Ammeter, A. P., \& Buckley, M. R. (2004). Leader political skill and employee reactions. The Leadership Quarterly, 15, 493-513.

Tugade, M. M., \& Fredrickson, B. L. (2004). Resilient individuals use positive emotions to bounce back from negative emotional experiences. Journal of Personality and Social Psychology, 86, 320-333.

Wanous, J. P., Reichers, A. E., \& Austin, J. T. (2000). Cynicism about organizational change: Measurement, antecedents, and correlates. Group and Organization Management, 25, 132-153.

Weiss, H. M., \& Cropanzano, R. (1996). Affective events theory: A theoretical discussion of the structure, causes and consequences of affective experiences at work. Research in Organizational Behavior, 18, 1-74.

Williams, L. J., Cote, J. A., \& Buckley, M. R. (1989). Lack of method variance in self-reported affect and perceptions at work: Reality or artifact? Journal of Applied Psychology, 74, 462-468.

\section{Appendix: German Items (and their back-translations to English)}

\begin{tabular}{llll}
\hline \multicolumn{1}{c}{$\begin{array}{c}\text { Positive emotion items } \\
(\text { denotes adaptation of JES item) }\end{array}$} & \multicolumn{1}{c}{$\begin{array}{c}\text { Negative emotion items } \\
(\text { (denotes adaptation of JES item) }\end{array}$} \\
\hline 1. Begeistert & Enthusiastic & 1. Traurig* & Sad \\
2. Angeregt & Aroused & 2. Angespannt & Tense \\
3. Mutig & Courageous & 3. Hilflos & Helpless \\
4. Inspiriert & Inspired & 4. Pessimistisch* & Pessimistic \\
5. Energetisiert & Energetic & 5. Frustriert & Frustrated \\
6. Zufrieden* (omitted) & Content (omitted) & 6. Angstlich* & Anxious \\
& & 7. Gelähmt* & Paralyzed \\
& & 8. Ruhig (reverse-scored) & Calm (reverse-scored) \\
\hline
\end{tabular}

\section{Perceived supervisor support items}

1. Das Management kümmert sich aktiv um meine Gefühle. Management shows active concern for my feelings.

2. Das Management unterstützt mich intensiv, um mir bei der Erfüllung wichtiger Prioritäten zu helfen.

Management provides intensive support in order to help me accomplish important priorities.

3. Das Management versichert uns, dass Hilfe verfügbar ist, wenn sie gebraucht wird.

Management assures us that help is available if it is needed.

4. Ich kann mich voll auf das Management verlassen.

I can fully rely on management. 


\section{Psychological hardiness items}

1. Ich bleibe trotz Rückschlägen engagiert bei der Erfüllung meiner Arbeitsaufgaben.

Despite setbacks, I remain committed to accomplishing job tasks.

2. Wenn es nötig ist, bin ich bereit, besonders hart zu arbeiten.

When necessary I am willing to work extra hard.

3. Wenn bei der Arbeit ein Problem auftaucht, bin ich normalerweise in der Lage, es zu bewältigen. When a problem occurs at work, I am usually able to deal with it.

4. Ich habe Kontrolle über die meisten Dinge, die mir bei der Arbeit passieren. I am in control of most things that happen to me at work.

5. Ich geniesse es, bei der Arbeit neuen Herausforderungen zu begegnen.

I enjoy facing new challenges at work.

6. Ich bin in der Lage, bei der Arbeit mit unerwarteten Problemen umzugehen. I am able to cope with unexpected problems at work.

\section{Employee cynicism items}

1. Manchmal kann man bemerken, wie sich die Leute in meiner Arbeitsgruppe mental zurückziehen. At times, you can notice people mentally withdrawing in my work group.

2. In meiner Arbeitsgruppe herrscht eine zynische Atmosphäre.

There is a cynical atmosphere in my work group.

3. Die Kommunikation in meiner Arbeitsgruppe ist oft negativ.

The communication in my work group is often negative.

4. Wir erleben viel Freude bei der Arbeit (reverse-scored).

We experience a lot of joy at work (reverse-scored).

5. Meistens arbeiten die Leute in meiner Arbeitsgruppe isoliert voneinander.

Most of the time people work in isolation from one another.

6. Es gibt viel Zynismus in meiner Arbeitsgruppe.

There is a lot of cynicism in my work group.

7. In meiner Arbeitsgruppe gibt es den Wunsch, etwas ins Rollen zu bringen (reverse-scored).

In my work group there is a desire to make something happen (reverse-scored). 